\title{
OCUPAÇÃO, CRESCIMENTO URBANO DESORDENADO E CRIMINALIDADE: A LUTA POR MORADIA NO BAIRRO DO COROADINHO
}

\section{RESUMO}

\author{
Marco Aurélio de Jesus Pio ${ }^{1}$ \\ Celio Roberto Pinto de Araújo ${ }^{2}$
}

O objetivo deste estudo é analisar o surgimento e formação do Bairro do Coroadinho a partir do crescimento urbano desordenado e como essas condições influenciam nos índices de criminalidade. No artigo foi utilizado pesquisa do tipo bibliográfica e o método materialismo histórico dialético. Nota-se que nas últimas décadas este bairro tem apresentado altos índices de criminalidade e caracteriza-se como um lugar onde prevalece a pobreza e ausência de políticas públicas necessárias para uma sobrevivência digna, portanto se busca estudar o desenvolvimento socioeconômico e sua relação com o crime, como categorias e objetos principais do trabalho.

Palavras-chaves: Ocupação; Crescimento Urbano; Criminalidade; Capitalismo; Coroadinho.

\section{OCCUPATION, URBAN GROWTH DISORDERLY AND CRIMINALITY: THE FIGHT FOR HOUSING IN THE COROADINHO}

\begin{abstract}
The objective of this study is to analyze the emergence and formation of the neighborhood of Coroadinho from disordered urban growth and how these conditions influence crime rates. In the article we used research of the bibliographic type and the dialectical historical materialism method. It is noted that in the last decades this neighborhood has presented high crime rates and is characterized as a place where poverty prevails and absence of public policies necessary for a dignified survival, therefore it is sought to study socioeconomic development and its relation with crime, as the main categories and objects of the work.
\end{abstract}

Keywords: Occupation. Urban growth. Criminality. Capitalism. Coroadinho.

\section{INTRODUÇÃO}

\footnotetext{
${ }^{1}$ Graduado em Direito (UFMA), Graduado em Segurança Pública (UEMA), Graduado em Filosofia (UEMA), Pós-Graduado em Docência do Ensino Superior (IESFMA), Pós-Graduado em Direito Penal e Processo Penal (UNESA-RJ), Pós-Graduado em Direito Militar (UNIATENEU-CE), Pós-Graduado em Gestão Pública (UEMA), Master of Business Administration em Direito e Processo do Trabalho (PITÁGORAS-MG), Mestre em Segurança Pública (IUPFA), Mestre em Desenvolvimento Socioespacial e Regional (UEMA), Doutorando em Direito (UVA/UNIFACVEST). Professor na Graduação e Pós-Graduação em Direito do Centro Universitário Estácio São Luís. Professor na Universidade Estadual do Maranhão. Coordenador dos Cursos de Pós-Graduação em Direito do Centro Universitário Estácio São Luís. Servidor Público Militar - Oficial Superior de Carreira. Email: maximusimperatore@yahoo.com.br

2 Graduado em Direito pela Faculdade do Maranhão. Especialista em Direito Tributário, Trabalhista e Previdenciário, Especialista em Políticas Públicas. Mestrando em Direito (UVA/UNIFACVEST). Atualmente é professor do Curso de Formação de Oficiais da Universidade Estadual do Maranhão. Comandante Geral do Corpo de Bombeiros Militar do Maranhão.
} 
O Bairro do Coroadinho surgiu de modo mais notável no cenário ludovicense na década de 1980, quando pessoas vindas do interior do Estado do Maranhão e de outras ocupações dentro de São Luís, resolvem se instalar às beiras do Rio Bicas e ali fixar moradia. Essa ocupação gerará uma disputa judicial pelas terras ocupadas e mesmo com decisão favorável para os moradores, não livrará a população do esquecimento e da ausência do Estado nesta região.

Como ocupação “irregular”, não teve prioridade do estado em políticas públicas de desenvolvimento, e por décadas sofreu do descaso e esquecimento, fazendo com que os moradores tivessem que sobreviver em um local com precárias condições de vida.

Assim, este estudo busca entender as condições em que se deu o surgimento e a formação deste bairro e porque os índices de criminalidades são altos nesta região, para isso se pretende ir além da mera narrativa dos fatos contados por quem detém interesse no discurso como forma de dominação ideológica.

Inicialmente se revisa a teoria do pacto social de Thomas Hobbes e sua influência sobre a dogmática penal para estruturar o conceito de crime sobre uma visão positivista.

Em seguida se analisa o contexto socioeconômico e espacial do Nordeste do século $\mathrm{XX}$ e as várias mudanças de cunho econômico e político nesta época, principalmente a criação da SUDENE e busca pela industrialização e colonização do Estado do Maranhão como políticas de desenvolvimento. No Maranhão, a alienação das terras públicas para o capital privado vai obrigar o deslocamento das pessoas para a capital, e na capital, os avanços no campo fabril, o aumento da densidade demográfica, assim como as política habitacionais apenas para a classe média vão levar à criação de Conjuntos habitacionais financiados pelo Banco Nacional de Habitação, mas também levará à expulsão da camada pobre da sociedade do centro da cidade para a periferia, sem qualquer apoio ou política de alocação pelo estado, gerando uma ocupação desordenada e muitas vezes ilegais do solo da capital maranhense.

É justamente neste tipo de ocupação irregular que se formará o Bairro do Coroadinho, onde pessoas e sem condições de morar no centro da capital, pelo custo de vida e condições de sobrevivência, acabam por invadir terras privadas ao redor do centro e passam a morar em habitações precárias, sem infraestrutura de agua, energia, esgoto, rede hospitalar, educação, segurança público entre outras condições básicas e dignas.

Na segunda metade da década de 1980 até o atual momento, o bairro sempre foi destaque nos meios de comunicação como um local violento, com alta criminalidade, e 
precárias condições de vida. E não é possível aceitar simplesmente que os moradores daquela região têm tendências inatas ao crime ou que por predileção resolvem quebrar as normas jurídicas impostas pelo Estado.

É por esta linha que se pretende a análise mais crítica e pormenorizada do surgimento e formação do bairro do Coroadinho e dos seus altos índices delitivos, procurando explicar que o cometimento de crimes é fruto da luta de classes e do sistema capitalista que gera a desigualdade social e protege determinados grupos utilizando-se de discursos ideológicos para convencer de que esta situação é "natural”.

A pesquisa é bibliográfica e tem suas bases em doutrina das mais diversas em âmbito da filosofia política, criminologia, economia, desenvolvimento, história, geografia política e espacial do Brasil, Nordeste e Maranhão. Também, utilizou-se de outros artigos científicos, publicações em revistas, monografias e teses. Adotou-se como método científico o Materialismo Histórico Dialético, onde se analisa a realidade utilizando a própria realidade como argumento, ou seja, analisando a luta de classes e meios de produção, partindo assim do concreto para o abstrato e por fim retorna-se ao concreto novamente. Se estabelece a partir de uma tese, contraposta por uma antítese e sendo reconstruída na síntese já que não é possível abstrações sem o concreto, o concreto é síntese de muitas determinações, ou seja, uma unidade do diverso.

\section{OCUPAÇÃO TERRITORIAL DO BAIRRO DO COROADINHO}

O processo de ocupação deste bairro aconteceu em março de 1977. Antes disso só havia alguns poucos moradores que usavam a terra para pequenas plantações e que começaram a viver ali a partir de 1940 vindos do interior e de outros estados, até aquele momento era chamada simplesmente de Sitio Caboclo. Porém, a influência do espaço urbano nesta área, vindo do centro para a periferia, vai ter início somente em 1960 quando o governo do estado começa a realizar algumas obras nas proximidades desta região. E, é somente na década de 1980 que vai ocorrer a ocupação em massa das terras do Coroadinho a partir da migração de moradores que já haviam se instalado anteriormente em outra área, chamada de Coroado e que fica nas proximidades. Esta ocupação (Coroado) era chamada assim por causa do nome fictício de uma Vila da novela Irmãos Coragem que foi exibida pela Rede Globo no início dos anos 1970. Assim, o nome Coroadinho foi escolhido exatamente pela proximidade 
territorial das duas ocupações, onde a primeira passou a ser conhecida como "Coroado Grande" e a mais nova "Coroadinho", nomes que permanecem até os dias atuais (MOTA, 1990).

Logo após o início do processo de ocupação, um suposto proprietário de nome Sandoval Silva Pimenta apresentou documentos que segundo ele atestava ser de sua propriedade aquela área que estava sendo ocupada e, com este argumento começou a vender lotes de terra já ocupados como se proprietário legítimo fosse, inclusive ignorando a presença daqueles que já estavam ocupando a terra. Isso também aconteceu com um lote que estava ocupado pela senhora Maria de Nazaré, e por este motivo o caso desencadeou uma ação judicial que se arrastou por cinco anos, onde Maria de Nazaré representando mais de 30 mil famílias ocupantes daquela área pedia que o Tribunal declarasse ilegítimo o direito do Sr. Sandoval Pimenta e desse a posse aos moradores (MOTA, 2019).

Além da doméstica Maria de Nazaré, a vitória na disputa judicial teve fundamental contribuição do Dr. Sandes Macedo, advogado que fez o levantamento do histórico da área e demonstrou que a documentação apresentada por Sandoval Silva Pimenta não tinha valor legal, e do frei Eurico e frei José ligados a paróquia Nossa Senhora da Glória que ajudaram financeiramente com o pagamento das custas processuais. Finalmente no dia 22 de fevereiro de 1984, a Segunda Câmara Cível do Tribunal de Justiça do Maranhão deu ganho de causa para os moradores confirmando que a documentação apresentada pelo suposto proprietário não tinha nenhum valor legal (FOCO, 2011).

Mas não se pode esconder que antes e durante este embate judicial pelas terras, houve muitos confrontos de moradores com a polícia, ora atuando por ordem do estado com uso de força "legítima", ora atuando em nome de interesses privados de terceiros, excedendose muitas vezes no uso da força, legalidade e permitindo a violência contra a população. De qualquer modo, daquele momento em diante o bairro começou a crescer em número populacional e consequentemente o seu perímetro inicial seguiu sendo ampliado paulatinamente.

IMAGEM 01 - Notícia do Jornal “O imparcial” de 23 de fevereiro de 1984 


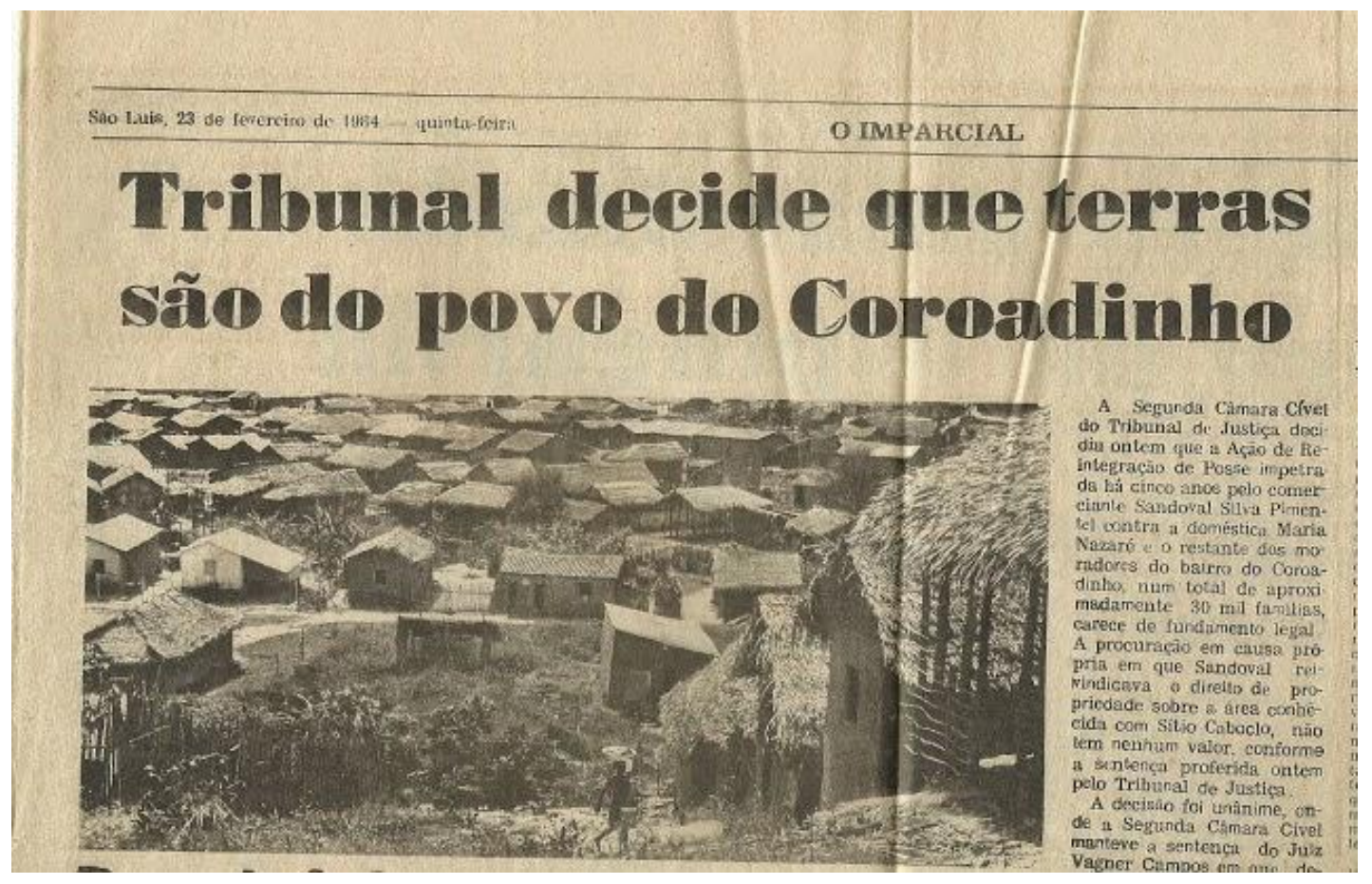

Fonte: http://coroadinhoemfoco.blogspot.com/2011/02/assim-foi-o-comeco.html

Já na década de 1990, o bairro passou a integrar a localização espacial e legal de São Luís através da Lei $\mathrm{n}^{\circ} 3.253$, de 29 de dezembro de 1992 que dispõe sobre o zoneamento, parcelamento, uso e ocupação do solo urbano, que em seu artigo $6^{\circ}$, XLI faz referência direta ao bairro do Coroadinho.

Entretanto, é fato que além da ocupação do bairro na década de 1980, o movimento de crescimento urbano "desordenado" não ficou estagnado, pois, conforme bem esclarece Joseane Ferreira Fróes, o bairro continua em plena expansão com a formação de vilas e aglomerações em suas adjacências, formando um verdadeiro polo urbano:

O Coroadinho surgiu por volta do ano de 1976, durante o governo de João Castelo. O terreno é pantanoso, com uma grande mata secundária, da qual os primeiros ocupantes tiveram que tirar a madeira. $\mathrm{O}$ bairro se forma a margem do Rio das Bicas. As famílias, em sua maioria, vindas do interior do Estado em busca de melhores condições de vida. Após a ocupação, a população começou a se expandir para outras áreas que foram sendo ocupadas dando origem a 16 (dezesseis) vilas e aglomerações que formam o bairro (FRÓES, 2004, p. 57)

Desta forma, diversas são as comunidades que foram surgindo nas adjacências do bairro formando o chamado Polo Coroadinho, tais como: Bom Jesus, Vila Primavera, Vila dos Frades, Vila Conceição, Sítio do Pica-pau Amarelo, Vila São Sebastião, Alto do São Francisco, Vila Pocinha, Vila Nice Lobão, entre outras. Hodiernamente, segundo a ONG 
Instituto Cidadania Ativa, o bairro é a quarta maior favela do Brasil e a primeira do Norte e Nordeste e, segundo o último censo realizado pelo Instituto Brasileiro de Geografia e Estatística (IBGE) pelo menos $65 \%$ dos jovens estão envolvidos em crimes ou consomem algum tipo de droga, enquanto 70\% das famílias ganham menos de um salário mínimo (G1, 2015).

Frise-se que na mesma década que o bairro do Coroadinho foi ocupado (1980), o Brasil como um todo conheceu o fenômeno da violência urbana, com crescimento explosivo da criminalidade como nunca visto antes no país. Esse fenômeno teve seus reflexos bem notáveis em diversas cidades e favelas do país. No bairro do Coroadinho os índices foram notáveis, e além do bairro se tornar palco de violência, também passou a ser sinônimo de criminalidade em todo o Estado do Maranhão a partir daquela década até os dias atuais.

Assim, tanto pelo seu rápido crescimento, como pela sua origem e evolução e principalmente pelo abandono do estado no que tange as políticas públicas voltadas para as necessidades básicas dos moradores dessa região, é que os altos índices de criminalidade tem sido uma constante diária neste bairro. Ressalta-se que este artigo não visa estudar o crime simplesmente como fenômeno jurídico a partir da dogmática positivista, mas analisar o crime como um fenômeno social, questionando suas origens e sua relação direta com o crescimento urbano desordenado e a ausência de políticas públicas que garantam necessidades básicas aos cidadãos (MOLINA; GOMES, 2002). O que se pretende doravante é entender qual a relação existente entre esse surgimento e crescimento desordenado do Bairro do Coroadinho e os altos índices de criminalidade ocorridos nas últimas décadas, sobre uma perspectiva da ciência política e da sociologia criminal.

\section{O PACTO SOCIAL E O SURGIMENTO DO CRIME EM HOBBES}

Inicialmente a base que será utilizada na busca pelas explicações supramencionadas encontra guarida na teoria contratualista de Thomas Hobbes ${ }^{3}$, que ao escrever o Livro Leviatã em 1651, entendia que os homens viviam em estado de natureza e em conflito uns com os outros, prevalecendo a força e a manutenção do medo de lesões e mortes violentas a qualquer momento. É neste contexto que surge a ideia de um pacto social com a finalidade de estabelecer o Estado (Leviatã) com poderes para manter o controle sobre o corpo social. Isso

\footnotetext{
${ }^{3}$ Thomas Hobbes foi um matemático, teórico político e filósofo inglês, autor de Leviatã. Nasceu em 5 de abril de 1588 e morreu em 4 de dezembro de 1679.
} 
seria efetivado com a criação de leis que regulassem as condutas e consequentemente sanções para os infratores, promovendo neste âmbito a ordem e harmonia (HOBBES, 2004).

No estado de natureza segundo sua visão de Hobbes (2004), os homens sempre tiveram direito a tudo e, desta forma poderiam sempre dispor do que suas paixões lhe despertassem desejo. A partir deste desejo poderia ter ou pegar para si qualquer coisa da forma, modo e quando quisesse, e nisso consistia a sua liberdade. O único obstáculo existente ao homem no estado de natureza era outro homem, haja vista que diante do mesmo objeto de desejo e tendo ambos o mesmo direito natural de ter e dispor, consequentemente haveria choque entre eles, mas lhes seria permitido agir pelo poder e força para assegurar suas paixões retirando a qualquer custo o outro homem do seu caminho, entendendo-se assim a ideia de liberdade no direito natural.

Mas, o problema principal desta situação se tratava do medo e insegurança, pois uma vez que cada um tinha direito sobre tudo e poderia usar dos meios que quisesse para retirar o outro homem do seu caminho de "liberdade" de ter e desejar, a sua integridade física e psíquica passavam a ficar ameaçados de modo a não ser possível uma plena convivência humana pacífica e harmoniosa, inclusive pelo constante medo da morte violenta. Hobbes vai dizer que o homem no estado de natureza vive em estado de guerra com os demais homens, ou como melhor se propalou ao longo dos séculos, que o homem é lobo do homem (HOBBES, 2004).

É neste contexto que Hobbes irá propor um contrato social entre os homens, posto que a partir deste contrato e pacto, o homem usando da razão decidirá abandonar o estado de natureza para passar ao estado civil. Hobbes chamará de direito natural a possibilidade que o homem tem de viver num estado de guerra de todos contra todos e pode ter o que quiser e usar da força e violência de modo legítimo para atingir o outro homem que se tornar um obstáculo à sua liberdade de desejo. Entretanto, percebendo que o direito natural consequentemente cabe a todos e por conta disso o homem vive uma vida embrutecida, insegura e com constante medo da morte, resolve-se criar normas e regras que ajudam a resolver e conter as paixões mútuas e conflitantes por meio das leis naturais e que por via de consequência leva os homens a celebrar um contrato, com cláusulas, limites, alcances e princípios, visando deixar o direito de natureza em segundo plano, ou melhor, como último recurso. Tal contrato deve partir da vontade de todos em renunciar seu direito natural de forma recíproca e sem a possibilidade de 
voltar atrás do que fora acordado, salvo se atentar contra sua própria vida ou nos casos de invalidade de suas cláusulas.

Tratando sobre o Estado Civil, Hobbes esclarece que o contrato social faz com que os homens renunciem seus direitos naturais para que outro ser, maior que eles possam lhe governar. Neste ponto Hobbes sugere a figura do Leviatã (monstro marinho bíblico) como representação do estado, que na sua concepção deveria ser a monarquia absolutista. Assim o estado, também chamado de "deus mortal", deve ser forte e temido, pois todos os homens lhes devem submissão e estão sob seu governo, inclusive os representantes do poder religioso (HOBBES, 2004). Nestas condições os homens passariam a ser súditos e deveriam observar e cumprir as leis que o estado impusesse, de forma que todos cumprissem o contrato social celebrado e, deste modo passassem a viver pacificamente e com mais segurança em detrimento do estado de natureza, em que outrora todos viviam tomados pelo medo.

É nesta esteira que se tem a ideia de crime como um ilícito penal, ou seja, um comportamento inadequado ou desalinhado com o pacto. E para que o pacto fosse cumprido haveria a necessidade de um controle social por parte do estado, uma vigilância constante para prevenir os delitos ou puni-los quando viessem a ocorrer. Segundo a criminologia, este controle qualificado como social pode ser formal e informal, sendo a principal diferença baseada no uso de normas jurídicas e instituições do sistema de justiça para possibilitar esse controle. Repise-se, portanto, que o crime, então, seria no aspecto formal, a quebra destas normas jurídicas pelos cidadãos que fizeram o pacto. Por outra visão, de cunho sociológico, pode-se dizer que o crime seria um comportamento indesejável e intolerável socialmente que precisa ser sancionado para manter a paz social.

A partir desta definição de crime extraído da visão hobbesiana do pacto social, é possível inferir a explicação de que no Bairro do Coroadinho os índices de criminalidades são altos porque as pessoas que ali residem não observam com rigor as regras do pacto, ou seja, as leis penais estabelecidas pelo Estado a todos "indistintamente" são quebradas constantemente das mais diversas maneiras. E por isso a necessidade da atuação das instituições do sistema de justiça enquanto representantes hodiernos do que Hobbes nomeou de Leviatã para poder manter o controle social e a observância do pacto a qualquer custo.

Desta forma, os indivíduos que moram no Bairro do Coroadinho acabam sendo etiquetados ou rotulados com criminosos de um modo geral, muitas vezes sem distinções. Essa linha de raciocínio se aproxima muito de outra teoria bem conhecida que, entretanto, não 
tem qualquer força atualmente, e que foi desenvolvida por Cesare Lombroso ${ }^{4}$, em sua obra "O homem delinquente" de 1876, por meio da qual sustentou a tese de que a criminalidade seria de ordem genética. Além disso, Lombroso sugeriu que o criminoso era portador de certos caracteres físicos inconfundíveis que o identificavam como tal (MOLINA; GOMES, 2002). A questão é que atualmente é cediço que não há criminosos inatos, ou seja, alguém que nasça criminoso, ou que tenha tendência geneticamente para cometer crimes. Entende-se que existem pessoas que, vivendo em determinados ambientes degradados e degenerados, acabam sofrendo influência dos fatores exógenos que as circundam e cometem crimes. Assim, o homem não é endogenamente um criminoso, mas, dependendo de seu habitat e das circunstâncias que lhe rodeia, pode vir a se tornar.

\section{A CONSTRUÇÃO SOCIAL DO CRIME NO BAIRRO DO COROADINHO}

Nas décadas de 1950 e 1960 os estudos sobre o desenvolvimento regional e urbano foram fortemente influenciados por teorias do desenvolvimento econômico, portanto, discutir a criminalidade no Coroadinho a partir da década de 80 do século passado exige uma discussão sobre o desenvolvimento, economia e criminalidade, portanto a perspectiva marxista parece ser a mais adequada para as questões que se propõe, pois busca analisar a organização do espaço e suas relações com a estrutura e dinâmica do modo de produção capitalista, assim como seus reflexos gerados pela luta de classes e a construção do conceito de crime e criminalidade neste contexto (BRANDÃO, 2007).

Primeiramente, deve-se lembrar, sem ousar um resgate detalhado, que a formação econômica do nordeste brasileiro teve a agricultura e pecuária como base nos primeiros séculos de sua "existência" e, destacou-se inclusive por ser a gênese da economia nacional (FURTADO, 2000). No século XX, no final da década de 1950, Celso Furtado, coordenou o Grupo de Trabalho para o Desenvolvimento do Nordeste (GTDN) e apresentou um relatório que fundamentou a estratégia inicial de ação da $\operatorname{SUDENE}^{5}$ para essa região (OLIVEIRA, 1981). Cabe registrar que a questão regional no Nordeste "nasceu" como um "problema" que, não por acaso, se redefine a partir de um projeto de industrialização brasileiro durante o

\footnotetext{
${ }^{4}$ Cesare Lombroso foi um professor universitário e criminologista italiano, nascido a 6 de novembro de 1835 , em Verona. Conhecido como pai da criminologia cientifica moderna.

${ }^{5}$ A Superintendência do Desenvolvimento do Nordeste foi criada originalmente pela Lei ${ }^{\circ}$ 3.692, de 1959, idealizada no governo do presidente Juscelino Kubitschek, tendo à frente o economista Celso Furtado, como parte do programa desenvolvimentista adotado.
} 
governo de Juscelino Kubitschek, cujos esforços tiveram como azimute a criação de um setor produtor de bens de consumo duráveis, formado no Brasil com investimentos do grande capital externo (VIEIRA, 2006).

Veja-se que a ideia de "desenvolvimento" do Nordeste surge com a suposta necessidade de industrialização da região. Entretanto, o país precisava de investimento de capital estrangeiro para lograr êxito neste projeto de industrialização do Nordeste. É, portanto, perceptível a forte influência do capital internacional por meio de forças políticas, para produzir uma paisagem geográfica favorável à sua própria reprodução e subsequente evolução no Nordeste brasileiro. É claro que não se pode crer, através do simples discurso do “desenvolvimento", ainda que proferido ou apoiado pelo Estado, em ingênuas intenções de proporcionar crescimento e melhorias desta região e seu povo. É necessário que se questione a quem interessa de fato tal desenvolvimento e que benefícios cada ator neste cenário do sistema capitalista vai obter, posto que o desenvolvimento capitalista será sempre desigual no tratamento da produção do espaço e das riquezas. (HARVEY, 2016)

Além de estimular a industrialização no Nordeste como discurso para superar as dificuldades geradas pela "velha" base agroexportadora nordestina, uma outra proposta central e que interessa a esta pesquisa, era tratar sobre a colonização do Maranhão. Isso porque a SUDENE, estudando o Nordeste, constatou a existência de uma progressiva e acelerada corrente migratória de cerca de cinco mil famílias por ano do sertão de Pernambuco, Paraíba, Rio Grande do Norte e principalmente do Ceará e Piauí para as áreas de Caxias, Bacabal e Pindaré-Mirim no Maranhão, à medida que se abria a BR-316 (GTDN, 1967). Os camponeses, fugindo das secas do Nordeste, saíam de seus locais de moradia em busca de novas terras para recomeçarem suas vidas com seus familiares. Contudo, na maioria das vezes esbarravam na grilagem das terras por grandes detentores do capital regional e políticos locais. Geralmente tinham que negociar para usar a terra, repartindo os lucros ou então seguindo em busca de outro local (WAGNER, 1981).

Sobre essa "grilagem" nas terras maranhenses, urge destacar que na década de 1970 com a criação da Companhia Maranhense de Colonização (COMARCO) e com a entrada em vigor da "Lei Sarney de Terras" o Governo do Estado do Maranhão passou a ter autorização legal para alienar terras públicas e implantar um grande projeto de colonização, que permitiu a venda de grandes extensões de terras para sociedades anônimas e grupos empresariais. Entretanto essas terras já eram ocupadas por pequenos produtores agrícolas e povos indígenas, 
que tiveram que sair destas áreas à força (conflitos judiciais e com a polícia), o que aumentou a tensão social e agravou os conflitos com os grandes empresários, levando o Maranhão a ser uma das regiões de mais intensos conflitos de terra em todo o país naquele momento, por causa da privatização das suas terras que, ao invés de servir para assentar os "retirantes" nordestinos fugidos da seca como previa o projeto da SUDENE, serviu ao capital privado mais uma vez (WAGNER, 1981).

Por tudo isso, muitas famílias resolveram migrar do interior para a capital do estado em busca de poder estabelecer moradia e tentar viver melhor, já que como em São Luís se concentrava o poderio do capital público e privado em relação ao restante do estado, então no imaginário dessa população campesina, provavelmente a vida poderia ser diferente, pois supostamente haveria emprego e condições melhores de vida.

Constata-se que desde a década de 1950 o crescimento demográfico de São Luís começou a se elevar consideravelmente e não parou mais de crescer, inclusive pelos principais motivos elencados anteriormente, entre outros fatores. Além do aumento populacional e da expansão urbana, também houve mudança na característica socioeconômica, isto é, de mercantil passa a ser fabril e futuramente industrial, dando ênfase dessa forma a uma nova classe social: o proletariado (operário), que será elemento essencial para se entender o surgimento de novos bairros e vilas na capital do Maranhão (CURVELOMATOS, 2014).

Portanto, no centro de São Luís, estavam concentrados não só a população com maior poder aquisitivo, político e econômico da capital, mas também seus comércios e negócios, assim como o poder público. Quanto maior o capital circulante em determinado local e as condições socioeconômicas da sua população, maior também serão os investimentos e melhorias em infraestrutura, saúde, educação, lazer e neste cenário cresce também a especulação imobiliária e o alto custo de vida. Esses altos custos e padrões de vida eram incompatíveis com a população pobre oriunda de migração ou aos nascidos dentro do sistema de reprodução do status quo social da própria capital.

Como as cidades crescem do centro para a periferia, nota-se que, quanto mais negócios e infraestrutura houver neste centro, maior será o custo para viver na referida localidade, e tanto maior será a força de expulsão/deslocamento, principalmente da classe trabalhadora, sem muitos recursos financeiros, para o setor periférico do perímetro urbano. 
Diga-se ainda, que, essa expulsão ocorre muitas vezes de forma sutil, sem grandes alardes, e outras vezes em meio a conflitos e uso da força.

Em 1964, o governo militar cria o Banco Nacional de Habitação (BNH) com o objetivo de alavancar a construção civil no Brasil a partir de financiamentos de moradias urbanas e populares, tentando colaborar para o fortalecimento da economia através da construção civil e estruturação das principais cidades no país, com os projetos das COHAB's (Companhia de Habitação Popular), inclusive no Maranhão, que vão ajudar no processo de expansão para além do centro e dos bairros fabris já existentes no "Caminho Grande" (BURNETT, 2012). Desses conjuntos habitacionais podemos destacar: Angelim, Bequimão, Cidade Operária, Radional, Jardim América, Turu, Vinhais e outros.

Por outro lado, quem não tinha condições de morar no centro ou não fazia parte da classe média trabalhadora para poder adquirir uma moradia por meio do BNH só teve uma opção: assentar-se "irregularmente" em áreas supostamente privadas e periféricas em relação ao centro, e sem ajuda do governo e qualquer infraestrutura estabelecer moradia e enfrentar lutas judiciais e embates com os supostos proprietários e muitas vezes a polícia.

É, portanto, diante deste contexto social, econômico e espacial do Nordeste, Maranhão e São Luís e, a partir do fluxo migratório de pessoas de outros estados para o Maranhão, do interior do estado para São Luís e do centro de São Luís para áreas periféricas sem apoio do Estado, que ocorreu o surgimento do bairro do Coroadinho (entre outros bairros) nas condições e circunstâncias que se deu na década de 1980, isto é, na busca por moradia e condições básicas e dignas de sobrevivência da população pobre.

Segundo o professor Sérgio Salomão Shecaira, a cidade, e, portanto, o bairro é um estado de espírito, um corpo de costumes e tradições e dos sentimentos e atitudes organizados, inerentes a esses costumes e transmitidos por essa tradição. Em outras palavras, não é meramente um mecanismo físico e uma construção artificial. Está envolvida nos processos vitais das pessoas que a compõem e se mostra como objeto imprescindível de qualquer análise sócio-criminológica, envolvendo a detecção dos fatores etiológicos da criminalidade (SHECAIRA, 2004)

Constata-se assim, que a ocupação de zonas periféricas sem qualquer regramento ou controle do Estado, reflete a imposição do capital privado na dominação das cidades, nos bairros mais nobres, nas relações de poder e, consequentemente na dominação da política, e é 
nestes limites que surgiu e se formou tal bairro com as características de precariedade inerente ao seu processo de forja. Tratando desse tipo de ocupação é possível deduzir que:

A existência de grandes quantidades de pobres, amontoados em moradias inadequadas, situa-se geralmente em terrenos ilegais e semilegais e são apenas em tais lugares que podem erguer ou alugar suas moradias (...). Nesses assentamentos os domicílios são geralmente precários, pequenos e habitados por muitas pessoas, são vulneráveis a sujeira, ratos, insetos e tem acesso limitado a serviços básicos, como coleta de lixos, esgotamento sanitário, e água de qualidade (....) sendo ilegais ou estando em desacordo com o zoneamento urbano, não há investimento públicos em nenhum aspecto. (MUELLER, 2007, p. 17)

No mesmo sentido:

Não é possível reduzir o tema da habitação unicamente ao imóvel que serve de abrigo à família, tornando-se necessário relacioná-lo com a própria cidade, isto é, com os serviços - transporte e saneamento, entre outros - e as oportunidades de trabalho, educação e cultura, que ela oferece aos seus habitantes. Tais aspectos são particularmente importantes no caso da Habitação Popular no Brasil, pois desde o século passado a população mais pobre vem sendo obrigada a se deslocar para áreas periféricas, desprovidas de urbanização e afastadas da vizinhança das demais classes sociais, sob o argumento de que somente terras baratas viabilizam imóveis baratos. (BURNETT, 2012, p. 79)

Deste modo, deveria o estado ter assentado estas pessoas em áreas apropriadas com o mínimo de infraestrutura, ou pelo menos propiciar a efetivação de políticas públicas para mitigar as problemáticas existentes nas áreas já ocupadas por conta própria pela população. Entretanto, o Estado atua como se não estivesse a serviço da classe pobre ou como se estes não tivessem legitimidade para serem beneficiados com políticas públicas, ou seja, age para a classe dominante que detém o poder econômico e é o núcleo do próprio poder político.

Deste modo, a população que ocupou inicialmente as terras do Coroadinho na década de 1980, passaram a ter que conviver com a insegurança, ausência de saúde, lazer, educação, moradias dignas dentre outras condições básicas de sobrevivência por muitos anos, esquecidos pelo estado (elite econômica) e rotulados de "periferia" com sentido pejorativo e tom de segregação até os dias de hoje.

Dentro desta perspectiva, o crime deve ser analisado no ambiente em que vive o homem, para que se possa detectar se referidos fatores exo-criminógenos que estão presentes (BARATTA, 2002). Veja-se, portanto, que este pensamento está na contramão da visão de Thomas Hobbes analisada no Leviatã, pois o Estado que pactua com o cidadão também se compromete a cumprir as normas que pactuou, não apenas fiscalizando a observação das normas, mas dando condições ao cidadão para observá-las. Na visão de Hobbes, do pacto surgem as regras que precisam serem cumpridas e quando são desobedecidas é preciso se 
aplicar sanções para reestabelecer a ordem e manter a paz social. Entretanto, a figura do Leviatã (Estado) é abstrata, e no mundo real e sensível são os homens que tomam a direção das instituições estatais. Por isso não é possível que se aceite que a vontade do estado não esteja alinhada com a vontade de grupos de homens e seus interesses pessoais. Assim, as regras que criam os crimes servem a interesses de classes e de grupos de pessoas (WACQUANT, 2008).

Os crimes nada mais são do que uma construção social a partir da luta de classes, os detentores dos meios de produção e do capital diante da desigualdade social e da pobreza, precisam proteger seu patrimônio para não serem saqueados, precisam evitar que outros homens lhe tomem a força "seus" bens. E para isso, criam normas penais com o intuito de proteger a si e aos seus por meio do discurso do pacto social indeclinável (GIORGI, 2017).

Por esse viés, quando se diz que o Bairro do Coroadinho sempre teve alto índice de criminalidade, estamos afirmando a partir da luta de classes que as pessoas que ali moram são produtos das desigualdades sociais, vivem a margem do sistema capitalista e quando não conseguem competir de igual acabam utilizando da força e quebrando as regras estabelecidas pela sociedade dos "iguais" (WACQUANT, 2008).

Neste pano de fundo se estabelecem os espaços sociais conflituosos. O centro não se mistura com a periferia. O aumento populacional desordenado acaba gerando um "inchaço" da cidade, que reflete diretamente na vida das pessoas, principalmente das que vivem nas margens da sociedade, ou seja, na periferia. O número de vagas em empregos começa a diminuir, gerando um grande exército de pessoas desempregadas ou subempregadas. Portanto, como se nota, a questão do aumento da cidade, são fenômenos geográficos que têm implicações sociológicas muito grandes e que, por essa razão, não podem passar despercebidos da análise da criminologia (FREITAS, 2002).

A clara concentração de riquezas nas mãos de uma minoria gera a desigualdade social, resultante de uma má distribuição de renda. Esta má distribuição de renda faz com que uma pequena elite tenha acesso ao que há de melhor no mercado de consumo, e de outro lado exclui os que sem dinheiro, não tem como adquirir referidos produtos e bens de consumo. Isso gera uma geografia humana muito peculiar (BATISTA, 2002). A elite se isola em fortificações, os condomínios fechados, e os pobres vivem nas favelas e periferias.

Estes ambientes urbanos degradados são focos certos de atividades violentas. Quanto maior o número de pessoas vivendo próximas umas das outras em condições precárias 
e de necessidades, maior a probabilidade de conflitos (MOLINA; GOMES, 2002). As pessoas vivem sob forte tensão. Frustradas pelas condições desumanas em que vivem, experimentando todo tipo de miséria, salários baixos, desmandos e abusos dos patrões ou busca sem sucesso por trabalho, podem levar as pessoas a chegarem em suas casas totalmente sobrecarregadas. E esta sobrecarga muitas vezes é liberada sobre a própria família, principalmente sob a forma de violência doméstica.

Colabora para este tipo de degradação psicológica, já fruto da degradação do ambiente em que se vive, a ausência de "espaços públicos de socialização". Não há praças, parques, bosques, centros de lazer. Os únicos ambientes "sociais" são os bares nos quais as pessoas vão não para se socializar propriamente, mas para afogar as frustrações num copo de bebida alcoólica e uma vez bêbados podem ser mais um foco de criminalidade. Os pais de família se socorrem dos bares, e cada vez mais o diálogo resta prejudicado com seus filhos. Os filhos, em toda esta conjuntura de esfacelamento familiar, ficam à própria sorte. Sem estrutura familiar, sem diálogo, sem sonhos ou perspectivas acabam soltos pelo mundo, vagando às cegas. Estas crianças e jovens crescem sem identidade e com uma personalidade problemática. São filhos e filhas órfãos de pais e mães vivos. Esta perda de identidade, principalmente na adolescência, deixa o jovem sem referencial. Este referencial é o modelo de conduta que todos tendemos a ter, sendo, na infância principalmente, a figura do pai ou da mãe. Sem o referencial, o jovem tende a se agarrar a qualquer coisa que supra sua carência afetiva.

Jovens sem identidade começam a se aglomerar em grupos, formando as gangues ou facções. Estas são aglomerados humanos que se formam, e isso psicologicamente falando, para a busca de um referencial, ou modelo. Assim, as gangues e facções são fruto ou reflexos da degradação familiar e esta, por sua vez, fruto da degradação social e urbana. A tendência das facções é sempre de cometimento de crimes e, portanto, do aumento da criminalidade das mais diversas formas (SUMARIVA, 2017)

A quem pense que toda essa problemática da criminalidade versus os problemas sociais que tem sua gênese na ocupação desordenada, podem ser resolvidos com a lei e aplicação de sanções. Infelizmente isso não é verdade, pois o sistema punitivo penal é seletivo e pune por amostragem e etiquetamento ${ }^{6}$. Andrade (2003) diz que tal seletividade se dá por

\footnotetext{
${ }^{6}$ Etiquetamento Social, é uma teoria criminológica surgida na década de 1960, nos Estados Unidos da América marcada pela ideia de que as noções de crime e criminoso são construídas socialmente a partir da
} 
dois motivos: o primeiro pela incapacidade estrutural de operacionalização do próprio sistema penal, pois se ele funcionasse haveria uma catástrofe social, assim não adianta inflacionar o sistema com leis e mais leis, pois ele funciona dentro de um limite, por isso a regra deste sistema seria a impunidade; em segundo lugar depende também da espécie de infração penal e das conotações sociais do seu autor, pois os grupos dominantes não aceitariam para si penas por condutas criadas a seu favor e não contra a sua classe. Em sua obra "Sistema penal máximo X cidadania mínima: códigos da violência na era da globalização" a autora continua:

\begin{abstract}
Isto significa, enfim, que impunidade e criminalização em vez de serem condicionadas pelas variáveis que formalmente vinculam a tomada de decisões dos agentes do controle social formal e que deveriam reenviar à conduta praticada, são condicionadas por variáveis latentes e não legalmente reconhecidas que reenviam à "pessoa" do autor (ANDRADE, 2003, p. 52).
\end{abstract}

E assim, na tentativa de aparentar funcionalidade do sistema penal que em essência serve à seletividade e etiquetamento da população marginalizada, tenta-se usar da força para solucionar os problema da criminalidade nestas periferias, quando a solução do problema deve se dar na base, ou seja, resolvendo as necessidades básicas da população com políticas públicas efetivas (GUIMARÃES, 2007).

\title{
CONSIDERAÇÕES FINAIS
}

A ideia de espaço e desenvolvimento não se limita a aspectos naturais, ela é criada a partir de um discurso ideológico de poder, e frise-se bem, de poder econômico. A produção e o gerenciamento do espaço assim como o seu desenvolvimento são categorias construídas historicamente na busca do poder econômico, logo, não se pode falar de desenvolvimento sem focar na discussão da economia.

As consequências e efeitos colaterais desse "desenvolvimento" também não são heranças naturais e inquestionáveis, porém resultam da luta de classes e da construção social do crescimento desigual do sistema capitalista, e da desigualdade social surgem também os delitos, como quebra de regras estabelecidas pela classe dominante à dominada, muitas vezes para garantir a proteção de seu patrimônio.

Após buscar informações de como se deu o surgimento e a formação do bairro do Coroadinho em São Luís, pode-se constatar muito mais que um simples levantamento de definição legal e das ações de instâncias oficiais de controle social a respeito do comportamento de determinados indivíduos. 
dados e fatos narrados unilateralmente por atores interessados na formação de discurso uníssono ideológico. Foi possível entender que a formação do bairro se deu no contexto da luta de classes e como efeito colateral do "desenvolvimento" desigual do sistema capitalista e sua busca pelo domínio dos meios de produção, além do que teve nos altos índices de criminalidade uma das consequências dessa formação nos moldes que ocorreu.

Em uma narrativa simplória dos fatos ocorridos em 1984 o que se pode visualizar é um grupo de pessoas que resolvem ocupar parte do solo urbano nas proximidades do Rio das Bicas, desmatando a área e construindo moradias precárias para poder ali se instalar. Parece uma fotografia simplista de um movimento social, estático temporalmente e isolado no campo político, econômico e espacial nas suas relações em níveis macro com o Estado, o Nordeste e ou até mesmo o restante do país. Mas não é, não mesmo!

O surgimento deste bairro é fruto da construção social do discurso desenvolvimentista que serve para uma classe que domina os meios de produção ou que pelo menos vivem adjacentemente à eles. Não há desenvolvimento igual para a classe dominada e a dominante. A construção do espaço com infraestrutura, educação, saúde, segurança e outros, são concentradas onde a elite econômica e política de uma localidade vive e tem seus negócios. Quem não faz parte desta elite precisa ser segregado sutil ou abruptamente. Sem políticas públicas eficazes para os pobres o único caminho que resta muitas vezes é procurar as periferias e tentar sobreviver com os efeitos da realidade desigual construída socialmente pelo capital e o Coroadinho é fruto desse sistema e dos fatores históricos econômicos elencados nesta pesquisa.

Neste contexto o crime é só mais um fator de segregação e proteção na luta pelo domínio do capital. O homem não pratica o crime porque nasce com tendência a delinquir, mas, quebra as normas jurídicas de acordo com o contexto em que se encontra inserido, e no contexto de desigualdade e miséria, será sempre mais fácil quebrar as regras e ser rotulado de criminoso. Portanto, o crime neste viés, é uma construção social de um contexto de desigualdade e luta de classes e fruto de um discurso de poder econômico pela classe que detém os meios de produção.

\section{REFERÊNCIAS}

ANDRADE, Vera Regina Pereira de. Pelas mãos da criminologia: O controle penal para além da (des) ilusão. Rio de Janeiro: Revan, 2017 (Coleção Pensamento Criminológico). 
ANDRADE, Vera Regina Pereira de. Sistema penal máximo X cidadania mínima: códigos da violência na era da globalização. Porto Alegre: Livraria do Advogado, 2003.

BARATTA, Alessandro. Criminologia Crítica e Crítica do Direito Penal: introdução à sociologia do direito penal. 3.ed. Rio de Janeiro: Editora Revan, 2002.

BATISTA, Nilo. Mídia e sistema penal no capitalismo tardio. Discursos sediciosos. Crime, direito e sociedade. Rio de Janeiro, ano 7, n. 12, 2002.

BRANDÃO, Carlos. Território e desenvolvimento: as múltiplas escalas entre o local e o global. Campinas: Ed. Unicamp, 2007.

BURNETT, Frederico Lago. São Luís por um triz: escritos urbanos e regionais. São Luís: EdUEMA, 2012.

CURVElO-MATOS, Heloísa Reis. Análise Toponímica de 81 nomes de bairros de São Luís/MA (Tese de doutorado). Universidade Federal do Ceará: Fortaleza, 2014.

FREITAS, Wagner Cinelli de Paula. Espaço urbano e criminalidade: lições da Escola de Chigaco. São Paulo: IBCCRIM, 2002.

FRÓES, Joseane Ferreira. Impactos sócio-urbanos no alto curso do Rio das Bicas: contextualizando o Bairro do Coroadinho. Monografia (Graduação em Geografia) Universidade Federal do Maranhão, São Luis, 2004.

FURTADO, Celso. Formação econômica do Brasil. 27. ed. São Paulo: Companhia Editora Nacional - Publifolha, 2000.

G1. No Coroadinho $65 \%$ dos jovens estão envolvidos em crimes, diz pesquisa (2015). Disponível em: http:/g1.globo.com/ma/maranhao/noticia/2015/06/no-coroadinho-65-dosjovens-estao-envolvidos-em-crimes-diz-pesquisa.html. Acesso em: 04 dez. 2017.

GIORGI, Alessandro de. A miséria governada através do sistema penal. Rio de Janeiro: Revan, 2017 (Coleção Pensamento Criminológico).

GUIMARÃES, Claudio Alberto Gabriel. Funções da pena privativa de liberdade no sistema penal capitalista. Rio de Janeiro: Renovar, 2007.

HARVEY, David. 17 Contradições e o Fim do Capitalismo. São Paulo: Editora Boitempo, 2016.

HOBBES, Thomas de Malmesbury. Leviatã ou Matéria, forma e poder de um Estado eclesiástico e civil. Tradução de João Paulo Monteiro e Maria Beatriz Nizza da Silva. São Paulo: Editora Nova Cultural, 2004 (Coleção Os Pensadores).

MINISTÉRIO DO INTERIOR (GTDN). Uma política de desenvolvimento econômico para o nordeste. $2^{\text {a }}$ ed. Rio de Janeiro: Departamento de Imprensa Nacional, 1967.

MOLINA, Antonio García-Pablos de \& GOMES, Luiz Flávio. Criminologia. 4. ed. São Paulo: Editora revista dos tribunias, 2002.

MOTA, Antonia da Silva. Coroadinho: histórico de ocupação de terras desde a década de 40 até os dias atuais. Monografia. (Graduação em História) - Universidade Federal do Maranhão. São Luis, 1990.

MOTA, Antonia da Silva. A luta por moradia popular em São Luís do Maranhão. São Luís: EDUFMA, 2019. 
MUELLER, C.C. Crescimento, Desenvolvimento e Meio Ambiente. In: Os economistas e as relações entre o Sistema Econômico e o Meio Ambiente. Brasília: FINANTEC-UNB, 2007.

OLIVEIRA, Francisco de. Elegia para uma re(li)gião: SUDENE, Nordeste. Planejamento e conflito de classes. 3. ed. Rio de Janeiro, Paz e Terra, 1981.

SHECAIRA, Sergio Salomão. Criminologia. Editora Revista dos Tribunais, 2004.

SUMARIVA, Paulo. Criminologia: Teoria e Prática. 4. ed. Niterói: Impetus, 2017.

VIEIRA, Flávio Lúcio R. Estado e questão regional: Por uma Economia Política da Região. SAECULUM - Revista de História. João Pessoa, jan./jun. 2006.

WACQUANT, LoÏc J.D. As duas faces do gueto: A penalização da Miséria e o avanço do neoliberalismo. São Paulo: Boitempo, 2008.

WAGNER, Alfredo. Anexo II: As secas do Nordeste e o Maranhão. Brasília, 1981. 